Acta Theriologica 45 (4): 507-524, 2000.

PL ISSN 0001-7051

\title{
Space use by Eurasian lynxes Lynx lynx in central Norway
}

\author{
Peter SUNDE*, Tor KVAM, Pål MOA, André NEGÅRD \\ and Kristian OVERSKAUG
}

Sunde P., Kvam T., Moa P., Negård A. and Overskaug K. 2000. Space use by Eurasian lynxes Lynx lynx in central Norway. Acta Theriologica 45: 507-524.

Habitat and spatial organisation of 11 radio tagged Eurasian lynxes Lynx lynx Linnaeus, 1758 were studied in a low-density (ca 0.3 ind $/ 100 \mathrm{~km}^{2}$ ) population in a boreal-alpine environment with low and temporally varying densities $(\leq 180 \mathrm{ind} / 100$ $\mathrm{km}^{2}$ in winter) of ungulate prey, primarily roe deer and semi-domestic reindeer. The use of habitat measured as 4 biome categories ranked from south boreal to alpine influenced mountain vegetation did not vary seasonally, but lowlands were much preferred to alpine habitats. Adult males moved almost 3 times farther per day in linear distance $(\bar{x}=5.9 \mathrm{~km}, n=3)$ than did females with kittens $(\bar{x}=2.0 \mathrm{~km}, n=4)$ or subadult females $(\bar{x}=2.5 \mathrm{~km}, n=6 ; p=0.002)$. Subadults $(n=5)$ dispersed $42 \pm 13(\bar{x}$ $\pm \mathrm{SE}$ ) $\mathrm{km}$ during the first 9 months of independence, but often visited their natal range during the first year on their own. Adult lynxes roamed over very large annual ranges [males: $1906 \pm 387 \mathrm{~km}^{2}(n=4)$, females: $561 \pm 102 \mathrm{~km}^{2}(n=6)$ ] that took $\geq 5$ days to pass through, independently of sex. The only male monitored over more than 1 year maintained 2 separate home ranges each year. The larger home ranges and the possible tendency towards less defined territory boundaries than previously reported for the species, may be caused by the lower prey and population densities, though culling of adult individuals may also have played a role by continuously creating empty gaps in the territorial mosaic.

Norwegian Institute for Nature Research, Tungasletta 2, N-7485 Trondheim, Norway

Key words: Lynx lynx, habitat use, movement, home range, dispersal

\section{Introduction}

As the most widespread felid in the northern Palaearctic (Heptner and Sludskii 1972, Nowell and Jackson 1996), the Eurasian lynx Lynx lynx Linnaeus, 1758 is well suited for comparison of individual and behavioural tactics of solitary carnivores under different environmental conditions. However, data have only been published from central-European populations, ie with relatively high densities $(0.9-5$ ind $/ 100$ $\mathrm{km}^{2}$ ) in environments with a stable, nonmigrating prey base (Breitenmoser and Haller 1993, Breitenmoser et al. 1993, Schmidt et al. 1997). In these areas, home ranges overlap only slightly between individuals of the same sex with male ranges encompassing 1-3 female ranges. This is the social pattern that is predicted for

\footnotetext{
* Present address: Department of Population Ecology, Zoological Institute, University of Copenhagen, Universitetsparken 15, DK-2100, Copenhagen Ø, Denmark, e-mail: PSunde@zi.ku.dk
} 
solitary carnivorous mammals whose intra-sexual territoriality secures females principal access to prey resources and males principal to females (Sandell 1989). However, resource monopolisation requires that the resources can be controlled and defended by the territory holder. This may be uneconomic if the resources are far apart and/or occur too unpredictably in space and time to be effectively controlled by the territory holder (Davies 1978). In case of the latter, other behavioural tactics than territoriality may therefore be adopted for foraging and mating. Due to the lower population densities in boreal areas, where prey is scarcer and may be seasonally migratory, the behavioural tactics of lynx may therefore not necessarily be the same as in richer and seasonably less varying environments. In the present paper, data on habitat use, dispersal, movement distances and home range sizes are presented from a low-density lynx population in a boreal-alpine environment with low prey densities. As a starting point, we would expect the same behavioural pattern as observed in central European populations though larger ranges should be expected due to the lower population densities of both predator and prey. However, because of the different ecological factors mentioned above, the possibility is open for other movement tactics and possibly also a looser social organisation in either or both sexes.

\section{Study area}

The study was carried out in the northern part of North-Trøndelag County, central Norway (Fig. 1). The total area that was used regularly by the radio-collared lynxes during the study, covered approximately $6700 \mathrm{~km}^{2}$ (Fig. 1). The topography rises from sea level to a maximum elevation of 1160 $\mathrm{m}$ a.s.l. The tree line is at around $300-400 \mathrm{~m}$ a.s.l. In the lowlands, continuous snow cover usually lasts from about 16 November to 15 May (this period is termed "winter" as opposed to "summer" for the rest of the year) and is often more than $1 \mathrm{~m}$ deep in forest habitats. Cultivated fields, coniferous forests and alpine vegetation cover 4, 32 and $64 \%$ of the total land area, respectively (data from Norwegian Yearbook of Statistics 1996, http://www.ssb.no/aarbox/). The lynxes primarily feed upon medium-sized ungulates ( $81 \%$ of the diet): roe deer Capreolus capreolus, semi-domestic reindeer Rangifer tarandus and domestic sheep Ovis aries, independently of habitat and season (Sunde et al. 2000). Roe deer were by far the most important prey of lynx in lowland habitats, whereas sheep and reindeer were the only ungulate prey in areas more than 1-2 km from farmland (Sunde et al. 1998a). On the basis of hunting bags and husbandry statistics, the approximate densities of ungulates in the study area were estimated to be $6-20$ roe deer $/ 100 \mathrm{~km}^{2}, 160$ reindeer $/ 100 \mathrm{~km}^{2}$ and, only in June-September, 250 sheep $/ 100 \mathrm{~km}^{2}$ (Sunde et al. 2000). The density of lynxes in the county was estimated at about $0.3 \mathrm{ind} / 100 \mathrm{~km}^{2}$ by January 1996, or $0.5 \mathrm{ind} / 100 \mathrm{~km}^{2}$ including dependent kittens (T. Kvam, unpubl.). Hunting of lynx was permitted in February and March until the local quotas were filled. There was a very high hunting pressure on the lynx population during the period of the study and hunting was responsible for all detected deaths of radio tagged lynxes (Sunde et al. 1998a).

\section{Material and methods}

The study was carried out from January 1994 through March 1997, when a total of 14 lynxes (11 independent individuals and 3 kittens, Table 1) were radio tagged. The lynxes were caught in box traps or in padded leg-hold traps placed near kills, and fitted with radio collars (Nybakk et al. 1996). A rough age estimate ( \pm 1 year) was made at capture on the basis of body size and tooth wear, and the ages of 


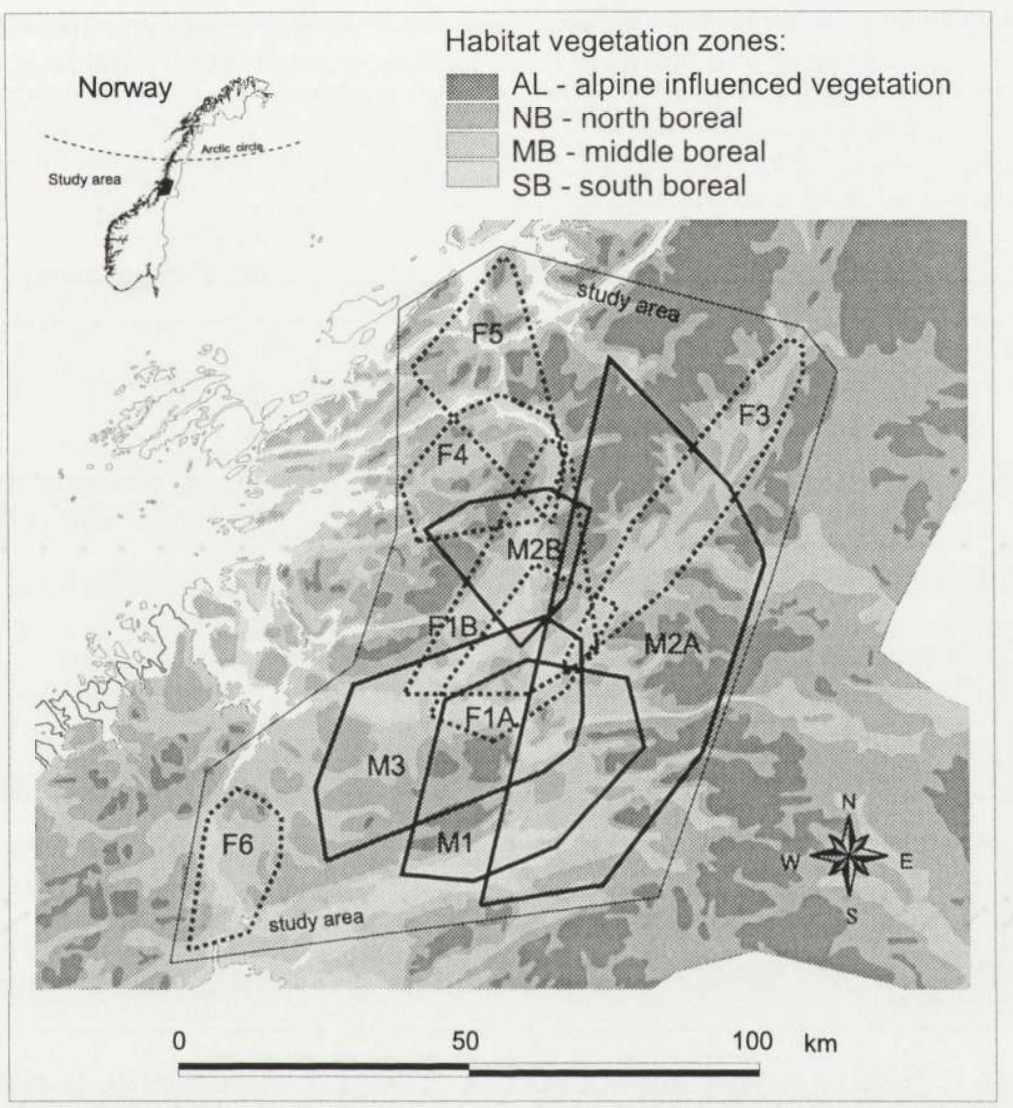

Fig. 1. Study area $\left(6700 \mathrm{~km}^{2}\right)$ with vegetation zones and home ranges (100\% minimum convex polygons) of adult (>1.75 year old) radio-collared lynxes (Table 1, see also Figs 4 and 5). The full lined polygons indicate the ranges of males outside the mating season (May-January), the dotted lines indicate the annual ranges of females. Note that the different polygons represent lynxes surveyed through different periods (see Tables 4 and 5 for further information). Blank areas along the coast are covered by marine influenced vegetation (shrub, heather) not found within the study area.

those that were later killed were determined precisely by counting the incremental lines in a canine tooth (Kvam 1984). The lynxes were grouped into 4 categories based on life history status: (1) subadults (from independence from the mother, usually at the end of April, to 1 March the following year), (2) adult females without offspring, (3) adult females with offspring, and (4) adult males. Three individuals changed status during the study and were treated as separate observations in their different life-history phases (Table 1 ).

Whenever possible, the lynxes were radio-tracked daily using standard telemetry techniques, in winter supplemented with tracking in the snow. If not prevented by weather, radio-tracking from fixed-wing aircraft was usually done every 1 or 2 weeks, except for the last year, when aerial tracking was done once a month.

After the end of the regular study the lynxes were checked opportunistically as long as their transmitters lasted. Additional information on lynxes with exhausted transmitters was also obtained through hunters' records, since all but 2 of the radio tagged lynxes had been shot by March 1999 . 
Table 1. Lynxes included in the study (those followed only as dependent juveniles are excluded). Ages are given in years and months on the first day of monitoring. Life history status is classified as subadults ( $\mathrm{SA})$, adult females with offspring $(\mathrm{AF}+)$, adult females without offspring $(\mathrm{AF}-)$ and adult males (AM). The survey periods last from capture until last telemetry location. No regular monitoring was done after April 1997. F1B was monitored indirectly through its radio-collared kitten (M4) until the kitten reached independence.

\begin{tabular}{|c|c|c|c|c|c|}
\hline Lynx & $\begin{array}{l}\text { Age } \\
\text { (yr/mth) }\end{array}$ & $\begin{array}{l}\text { Body } \\
\text { mass } \\
(\mathrm{kg})\end{array}$ & Status & Period of survey & Cause of termination \\
\hline M1 & $3 / 10$ & 22.5 & $\mathrm{AM}$ & 2 Apr $94-25$ Sep 94 & Shot illegally \\
\hline M2 & $\approx 5 / 0$ & 24.0 & $\mathrm{AM}$ & 18 Mar $95-24$ Mar 97 & $\begin{array}{l}\text { Killed by hunters, who found it fatally } \\
\text { wounded by another male in Feb } 1999\end{array}$ \\
\hline M3 & $2 / 10$ & 20.5 & $\mathrm{AM}$ & 15 Apr $95-25$ Feb 96 & Shot \\
\hline M4 & $0 / 11$ & $?$ & SA & 22 Apr 96 - 24 Feb 97 & Shot \\
\hline M5 & $0 / 11$ & 14.0 & SA & 5 May $96-3$ Feb 97 & Shot \\
\hline $\mathrm{F} 1$ & $\begin{array}{l}\approx 2 / 8 \\
\approx 4 / 3\end{array}$ & $\begin{array}{l}15.0 \\
-\end{array}$ & $\begin{array}{l}\mathrm{AF} ?- \\
\mathrm{AF}+\end{array}$ & $\begin{array}{l}16 \text { Jan } 94-11 \text { Apr } 94 \\
21 \text { Aug } 95-20 \text { Apr } 96\end{array}$ & $\begin{array}{l}\text { A: Transmitter failure } \\
\text { B: Abandoned its radio-collared kitten }\end{array}$ \\
\hline $\mathrm{F} 2$ & $0 / 8$ & 9.5 & SA & 24 Jan $94-25$ Feb 95 & $\begin{array}{l}\text { Transmitter failure, shot in Feb 1996, } \\
\text { while followed by } 2 \text { kittens }\end{array}$ \\
\hline F3 & $1 / 8$ & 15.0 & $\begin{array}{l}\mathrm{SA} \\
\mathrm{AF}-\end{array}$ & $\begin{array}{l}9 \text { Feb } 94-1 \text { Mar } 94 \\
1 \text { Mar } 94-29 \text { Nov } 94\end{array}$ & $\begin{array}{l}\text { Failed to reproduce in 1994. Transmitter } \\
\text { failure. Shot in Feb 1996, while followed } \\
\text { by } 2 \text { kittens. }\end{array}$ \\
\hline $\mathrm{F} 4$ & $\approx 4 / 8$ & 16.5 & $\mathrm{AF}+$ & 7 Apr $94-6$ Oct 95 & $\begin{array}{l}\text { Reproduced successfully in } 1994 \text { and } 1995 \\
\text { (2 kittens each year). Transmitter failure. }\end{array}$ \\
\hline F5 & $\begin{array}{l}0 / 8 \\
1 / 9\end{array}$ & $\begin{array}{l}12.5 \\
16.5\end{array}$ & $\begin{array}{l}\mathrm{SA} \\
\mathrm{AF}+\end{array}$ & $\begin{array}{l}21 \text { Apr } 94-1 \text { Mar } 95 \\
1 \text { Mar } 95-25 \text { Feb } 96\end{array}$ & $\begin{array}{l}\text { Reproduced successfully in } 1995 . \\
\text { Shot together with its } 2 \text { kittens }\end{array}$ \\
\hline F6 & $\begin{array}{l}0 / 9 \\
1 / 9\end{array}$ & $\begin{array}{l}12.5 \\
-\end{array}$ & $\begin{array}{c}\mathrm{SA} \\
\mathrm{AF}+\end{array}$ & $\begin{array}{l}2 \text { Mar } 95-1 \text { Mar } 96 \\
1 \text { Mar } 96-15 \text { Apr } 97\end{array}$ & $\begin{array}{l}\text { Reproduced successfully ( } 1 \text { kitten) in } 1996 \text {. } \\
\text { Shot (under license) for killing sheep in } \\
\text { Aug } 1998 \text {, while followed by } 1 \text { kitten. }\end{array}$ \\
\hline
\end{tabular}

\section{Habitat use}

For the habitat use analyses, the landscape (Fig. 1) was categorised into 4 types of vegetation following a south-north gradient, as digitised in a Geographic Information System (GIS; גrc Info ver. 2.1, ESRI). The 4 habitat categories were (1) south boreal vegetation, (SB, $9 \%$ of the study area): spruce Picea abies forest with elements of southern deciduous species (Ulmus glatra, Corylus avellana); (2) middle boreal (MB, 28\%): spruce forest with some pine Pinus sylvestris and birch Betula pubescens; (3) north boreal (NB, 36\%): alpine-like coniferous forest and shrub vegetation (primarily spruce, pine, and birch), and (4) alpine influenced vegetation (AL, 23\%): sub-alpine heather vegetation and alpine tundra.

Only fixes originating from aerial trackings were used in the habitat analyses to ensure that sampling was unbiased by varying road access to different habitats. To test whether the lyuxes differed 
in habitat use between summer and winter, the mean "elevation" of the used habitat was tested on the mean scores of the habitat composition (scored as 1-4 from SB to AL, see appendix) with a related $t$-test on 9 lynxes with $\geq 5$ of aerial fixes from each season. Since there was no significant difference between the seasons (see Results), the habitat use data for each lynx were pooled over all seasons. Habitat preference (ie use vs availability) was analysed by using compositional analyses (Aebischer et al. 1993) on the log ratios of used and available habitat proportions (substituting 0.005 for 0 -values). The significance was tested on 9999 randomisations in a SAS macro (SAS version 6.12 for Windows, SAS Inst.). The habitat availability for each individual was measured with a random-point method, where random availability-fixes were generated around the original fixes, 1.5 to 2.5 times the mean distance between the habitat borders in the area. This availability measure gives the habitat availability within 2-6 km from each true location, or about a night's walk for a lynx, and should be approximately equal to habitat availability at the 3rd order, ie within the home range level (Johnson 1980). The habitat composition of the availability fixes was also tested against the habitat composition of the study area as a measure of the habitat requirements (equivalent to habitat selection on the 2nd order Johnson 1980). In the latter analysis, a 10th lynx with too few aerial fixes for the first analysis was added to the data set. All data on habitat use and availability on 2nd and 3rd order level are given in the appendix.

\section{Movement distances per day}

The daily, linear movement distances (DLM) were measured between consecutive day locations of resting lynxes. DLM was not calculated for females returning to dens with neonatal kittens or for the first week after immobilisation and tagging. At least 6 observations of day-to-day movements were required for a lynx to be included in the analyses. The differences between status-groups in median, mean and maximum DLMs were tested in a 2-way randomisation ANOVA with 9999 permutations (Manly 1997), since data could not be assumed to be parametric.

\section{Subadult dispersal and space use of adults}

A juvenile was considered independent the first day after it was observed together with its mother for the last time, usually in late April. Dispersal from the natal range was measured in February the year after independence (at an age of 21 months), the time of the first mating for at least 3 out of 4 of the young females. Since the mother's range was known for sure in only one of the cases, dispersal distance was measured from the point where the subadult was found on its own for the first time. For 4 out of 5 subadults this was the point where they were caught.

Home range analyses were conducted on lynxes older than 1.75 years (by 1 March the year after independence), the approximate time of first mating after which a resident-like behaviour was observed in most individuals as proved in autocorrelation analyses (see below). The area use was measured as 100\% minimum convex polygons, (100\% MCP; Mohr 1947) and as 95, 75 and 50\% adaptive kernels (Worton 1989). One fix per day was used, ie accepting autocorrelated fixes as recommended by Harris et al. (1990) and De Solla et al. (1999), but avoiding clumped data sampling as would be the case if all fixes were used. Due to the extensive range use of the lynxes, it is likely that the data obtained from ground bearings failed to find many "outliers" and therefore in some cases underestimated the total range size. However, little can be done about this possible bias since an analysis based only on aerial fixes would lose disproportionately much in information because of too few data points.

The lynxes' ability to patrol their ranges against intruders was measured as the autocorrelation coefficient, $\Delta \mathrm{T}$, the necessary time span there had to be between consecutive fixes for them to be independent of each other, ie when Schoener's ratio $\left(t^{2} / r^{2}\right.$, where $t^{2}$ is the mean squared distance between successive observations and $r^{2}$ is the mean squared distance from the fixes to the arithmetic mean of the fixes) approached 1.96 at 3 successive intervals (Swihart and Slade 1985, Kenward and Hodder 1996). $\Delta \mathrm{T}$ is thus proportional to the time the lynx would need to patrol its range, ie low values indicate high potential of discovering intruders and high values a low potential. If no $\Delta T$-value could be established, this indicated that the lynx either did not use the same home range at all (ie had a 
"floating" home range) or that the time span to roam it was longer than the survey perod (Swihart and Slade 1985).

The software Ranges V (Kenward and Hodder 1996) was used for all range analyses. Default options were used for the kernel estimations, and 1 day formed the minimum sampling inerval in the autocorrelation analyses. Inter-sexual differences in range sizes (2-tailed $p$ ) were tested on 9999 randomisations with 2-sample randomisation tests (Manly 1997), since the measures could not be assumed to be parametric. Range overlap between 2 individuals during a given period was measured as the proportion of fixes of 1 individual within the $100 \%$ MCP of another. This was done instead of comparing the overlap of polygon areas, since that method would be more liable to give misleading results due to the polygons overlapping over huge areas of avoided habitat, ie highland habitats between valleys.

\section{Results}

\section{Habitat use}

The lynxes did not differ in the mean ranking indices of habitats on a north-south scale between winter and summer $\left(t_{8}=0.35, p=0.73\right.$, see Appendix for raw data). The habitat zones were not used in proportion to their availability measured with random fixes (Wilk's lambda $=0.118, p=0.002, n=9$ ), and the habitat compositions of the availability fixes deviated from those from the entire study area (Wilk's lambda $=0.156, p=0.001, n=10$ ). At both scale levels, the 2 lowland categories were the most preferred, whereas alpine areas were avoided (Table 2, Fig. 2).

Table 2. Ranking matrices of habitat preference of lynxes in central Norway on 2nd and 3rd order level of scales (see text). The proportional differences in habitat selection between different habitat categories are measured as the mean differences in selectivity index $\left[\ln \left(\mathrm{U}_{a} / \mathrm{A}_{a}\right)-\ln \left(\mathrm{U}_{b} / \mathrm{A}_{b}\right)\right.$, where $\mathrm{U}_{i}$ and $\mathrm{A}_{i}$ are the utilised and available proportions of habitat $i$. The relative difference in preference between two habitat categories can be expressed as the anti- $\log _{e}$ to the value in the matrix. Habitat categories: $\mathrm{AL}$ - alpine influenced vegetation, $\mathrm{NB}$ - north boreal vegetation, $\mathrm{MB}$ - middle boreal vegetation, and $\mathrm{SB}$ - south boreal vegetation. The habitat types are ranked according to increasing preference. The utilisation data originate exclusively from tracking from fixed-wing aircraft. The pairwise differences within the matrices were tested on 9999 randomisations. Levels of significance in the pairwise comparisons: ${ }^{*} p<0.05,{ }^{* *} p<0.01$.

\begin{tabular}{|c|c|c|c|c|c|}
\hline Habitat & $\mathrm{AL}$ & NB & MB & SB & Rank \\
\hline \multicolumn{6}{|c|}{ 2nd order level } \\
\hline $\mathrm{AL}$ & - & $-0.34^{*}$ & $-0.85^{* *}$ & -0.60 & 0 \\
\hline NB & $0.34^{*}$ & - & $-0.51^{* *}$ & -0.27 & 1 \\
\hline MB & $0.85^{* *}$ & $0.51^{* *}$ & - & 0.24 & 3 \\
\hline SB & 0.60 & 0.27 & -0.24 & - & 2 \\
\hline \multicolumn{6}{|c|}{ 3rd order level } \\
\hline $\mathrm{AL}$ & - & $-2.12^{* *}$ & $-3.07^{* *}$ & $-2.85^{* *}$ & 0 \\
\hline NB & $2.12^{* *}$ & - & $-0.95^{* *}$ & -0.73 & 1 \\
\hline MB & $3.07^{* *}$ & $0.95^{* *}$ & - & 0.22 & 3 \\
\hline SB & $2.85^{* *}$ & 0.73 & -0.22 & - & 2 \\
\hline
\end{tabular}




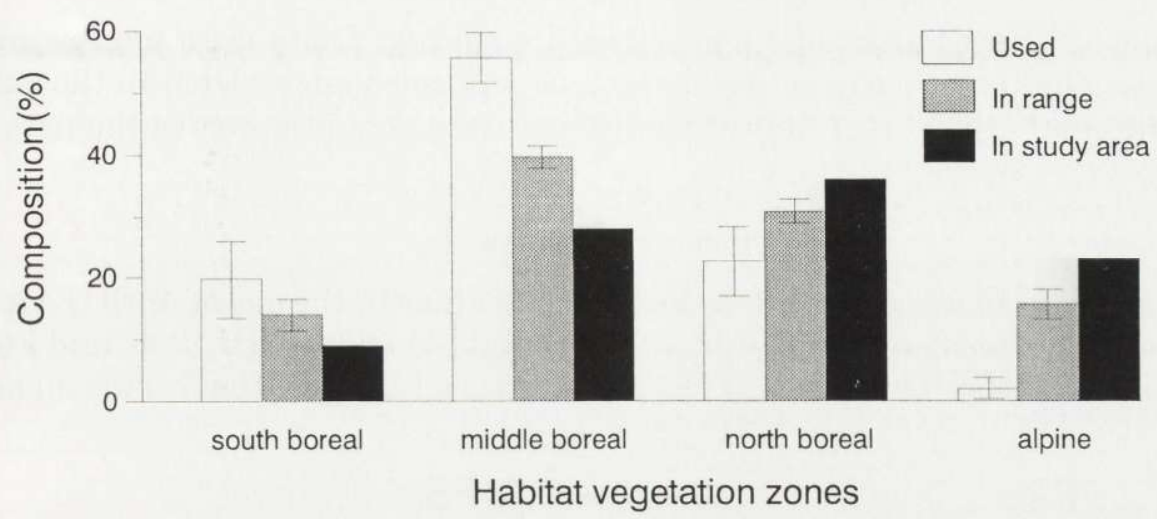

Fig. 2. Habitat composition (mean $\pm \mathrm{SE}$ ) used by 9 lynxes (only aerial fixes), available in the range (availability on 3rd order level), and available in the $6700 \mathrm{~km}^{2}$ study area (availability on 2rd order level), respectively.

\section{Movement distances}

On average, adult males moved $5.9 \mathrm{~km}$ per night in linear distance or 3 times further per day than females with offspring (Table 3). Subadults and adult females

Table 3. Daily linear movement distances (DLM). Differences in DLM among the status groups were tested with a randomisation test on 9999 permutations. The data is throughout the year. However, in females with offspring data from the neonatal period (where the offspring is immobile) is excluded.

\begin{tabular}{|c|c|c|c|c|c|}
\hline \multirow{2}{*}{ Status group } & \multirow{2}{*}{ Lynx } & \multicolumn{3}{|c|}{ DLM (km) } & \multirow{2}{*}{$n$ day } \\
\hline & & Mean & Median & Maximum & \\
\hline \multirow[t]{7}{*}{ Subadults/females } & F1A & 1.6 & 0.5 & 8.7 & 17 \\
\hline & F2 & 3.5 & 2.3 & 12.0 & 28 \\
\hline & F3 & 3.6 & 3.5 & 10.8 & 42 \\
\hline & F5A & 2.4 & 2.1 & 7.1 & 34 \\
\hline & F6 & 1.8 & 0.6 & 9.8 & 29 \\
\hline & M4 & 1.9 & 0.8 & 7.5 & 23 \\
\hline & $\bar{x}$ & 2.5 & 1.6 & 9.3 & \\
\hline \multirow[t]{5}{*}{ Females without kittens } & F1B & 1.1 & 0.7 & 4.4 & 18 \\
\hline & F4 & 1.0 & 0.9 & 2.3 & 11 \\
\hline & F5B & 3.0 & 1.7 & 13.0 & 61 \\
\hline & F6B & 2.8 & 2.0 & 10.4 & 9 \\
\hline & $\bar{x}$ & 2.0 & 1.3 & 7.5 & \\
\hline \multirow[t]{4}{*}{ Adult males } & M1 & 4.9 & 1.4 & 17.6 & 23 \\
\hline & M2 & 6.7 & 5.0 & 25.9 & 43 \\
\hline & M3 & 5.4 & 3.5 & 17.5 & 22 \\
\hline & $\bar{x}$ & 5.9 & 3.6 & 21.0 & \\
\hline$p=$ & & 0.002 & 0.13 & 0.002 & \\
\hline
\end{tabular}


without offspring moved like females with offspring. There were too few individuals to allow us to test whether males had performed longer DLM in the rutting season than in the rest of the year, but there were no indications in the data that this was the case.

\section{Dispersal of offspring}

The radio-collared females left their grown kittens by the end of April (F4 left its 2 untagged kittens around 20 April 1995, F1 left M4 on 20 April 1996, and F6 was still with its kitten when tracked for the last time on 15 April 1997). Two subadults

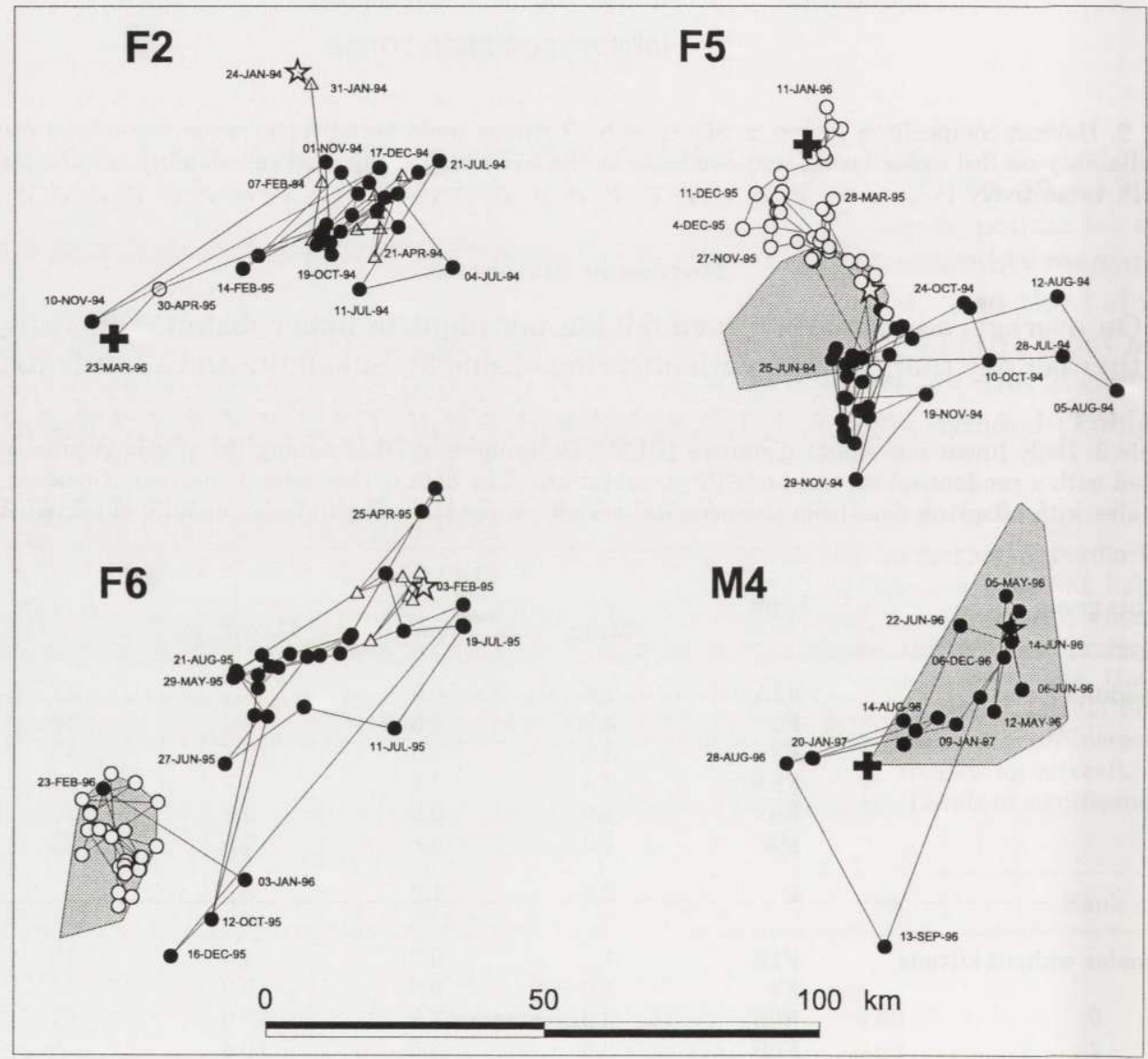

Fig. 3. Dispersal of 4 subadult lynxes from independence of their mother in late April (F5 and M4) or from capture on their own without mother in late winter (F2 and F6). Filled dots indicate locations from late April until 1 March the following year and white dots indicate locations after 1 March, ie, after about 9 months of independence. The period February-March, when F2 and F6 were surveyed as grown kittens without their mother (F6 was with a sibling), is indicated with triangles. Stars indicate the first days of recorded independence and crosses indicate deaths. For F5 and M4, the shaded polygons indicate the known (M4) or presumed (F5) home ranges of their mothers. For F6, the shaded area indicates a home range established after 1 March the year following after independence (as 21 months old). 
(F2 and F6, Table 1) that were on their own when caught in late winter were probably left by their mother. The dispersal seemed to be a stepwise process in which the young lynxes often returned to previously visited ranges (Fig. 3). The birth area was visited regularly during the following autumn and winter by at least 3 out of 5 subadults (Fig. 3). At the beginning of February (ie when they were 21 months old), 5 subadults were on average $42 \mathrm{~km}(\mathrm{SE}=13$, range 4-79 $\mathrm{km}$ ) from their origin the preceding spring. The 6th subadult that reached independence in spring 1997 after the termination of the study, was shot in February 1998, $40 \mathrm{~km}$ from where it was last observed with its mother.

\section{Area use by adults}

Autocorrelation analyses revealed stable home ranges with $\Delta \mathrm{T}$ varying from 5 to 23 days (Tables 3 and 4), independently of sex (Mann-Whitney $U$-test: $p>0.2$ ). However, in one lynx (adult female F5), no $\Delta \mathrm{T}$ was found for the 10 months survey period, indicating that all fixes were autocorrelated, ie that it did not have a stable home range. Fig. 3 illustrates that this lynx, after having reproduced for the first time, stayed ca 2 months south of the breeding range and then it moved north into areas, where it had never been before.

On an annual basis, all adult males used areas of $>1000 \mathrm{~km}^{2}$ (Table 4, Figs 1 and 4). During the mating season, the males did not use larger areas than during other times of the year (Table 4) but the "rut ranges" were often found in the periphery of where they stayed during the rest of the year (Fig. 4). The females used 3.4 times smaller total annual ranges than did the males as revealed from $100 \%$ MCPs $(p=0.002)$. Since the females reduced their home ranges considerably when they had neonatal kittens (Table 5, Fig. 5) a reasonable male-female comparison based on kernel range estimates should not include data on females from this period. When these are excluded from the analyses, the male-female ratios of 95,75 and 50\% kernel home ranges were $1.8(p=0.02), 1.5(p=0.03)$ and $1.1(p=0.15)$, respectively, indicating a more truncated range distribution function of males than of females. In other words both sexes had similar size core areas, but males used much larger and more diffuse areas outside these cores.

The males' ranges encompassed several females (Fig 1). Data from more than a single year exists for only one male (M2), which had separate home ranges before and after the spring rut in 1996 (Fig. 4) and made long excursions at all seasons, covering a total area of $4240 \mathrm{~km}^{2}(100 \% \mathrm{MCP})$ during the whole survey. When shot, 2 years after the completion of the study, it was outside both of the two previous home ranges (Fig. 4). The two simultaneously surveyed neighbouring ranges of males M2A and M3 did not overlap (Fig. 1).

Apart from $\mathrm{F} 5$ for which no $\Delta \mathrm{T}$ value could be estimated, the ranges of females tended to be relatively stable between years. F1 stayed in approximately the same area in 1995-1996 as in the spring of 1994 (Fig. 5), F4 raised kittens in the lair for two consecutive summers, and F2, F3 and F6 were shot relatively close to where their transmitters failed one year earlier (Figs 3 and 5). Three neighbouring adult 


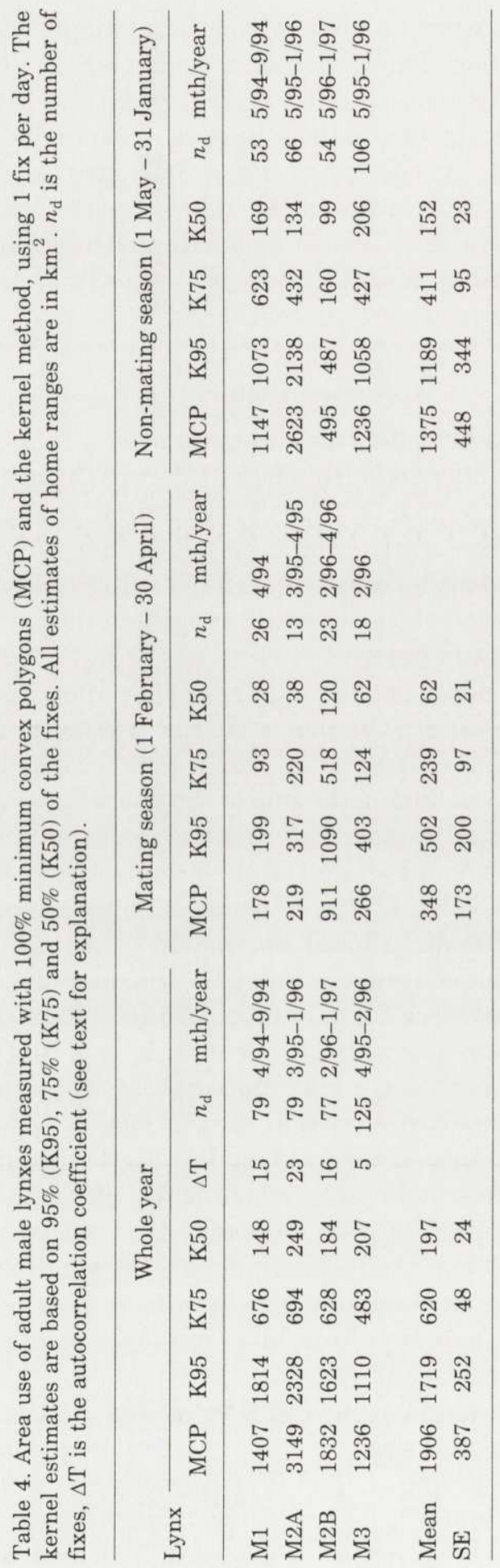




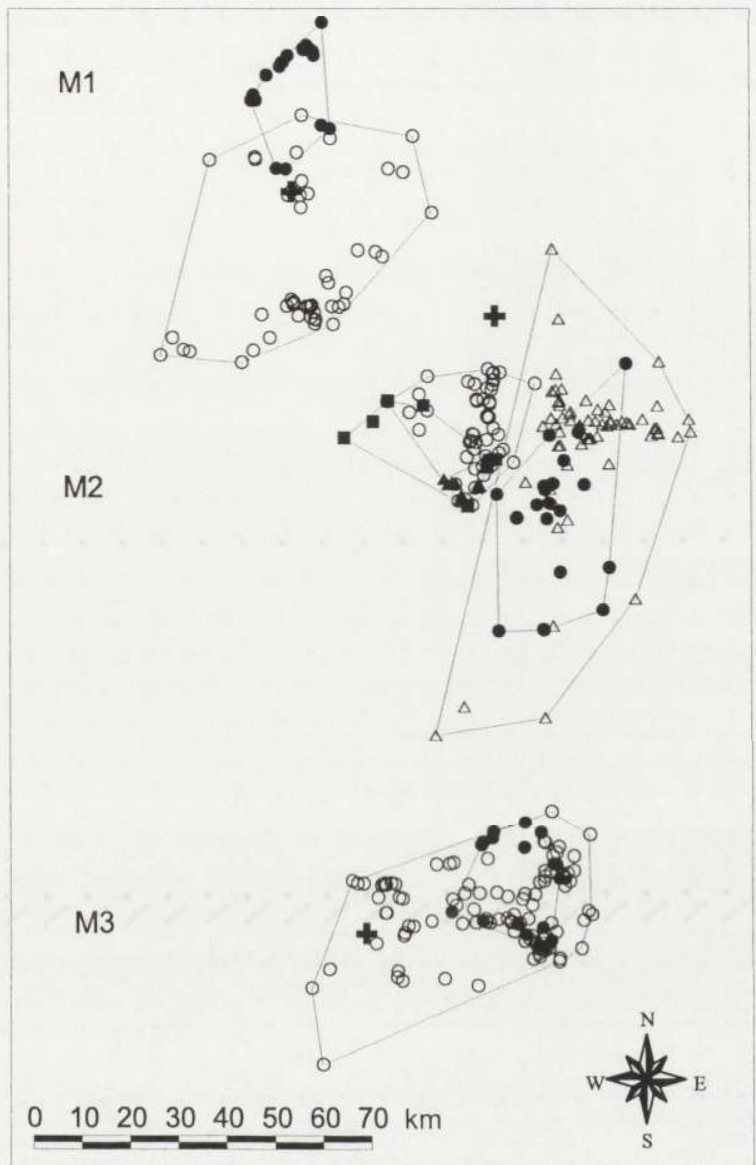

Fig. 4. Spacing ( $\max 1$ fix per day) of the 3 adult male lynxes divided into a mating season (filled dots, February-April) and a non-mating season (open dots, May-January). The males are shown individually, and the relative distribution of their ranges is shown in Fig. 1. The crosses indicate the locations where the males were shot. The survey periods and range sizes for the different males are given in Tables 1 and 3. M2 was the only male surveyed over more than one year, as indicated by the symbols: A - March-April 1995, $\Delta$ - May 1995 - January 1996, - February-April 1996, O - May 1996 - January 1997, - - February-April 1997. M2 was shot in February 1999, 2 years after completion of the study.

females (F1, F4 and F5) were studied concurrently from 22 August through 6 October 1995 (Fig. 5b). During this period, F5 overlapped in total ranges with F1 and F4 (32 and 79\%, respectively). It is likely that F5 was F4's daughter since the two lynxes originally were caught few days apart in the same box trap within F4's range. In spring 1995, two very young subadults (F6 and its untagged sibling) stayed for 2 months in the same area as an adult female with kittens (the latter was discovered through snow-tracking alone, but was probably F1, see Fig. 5). 


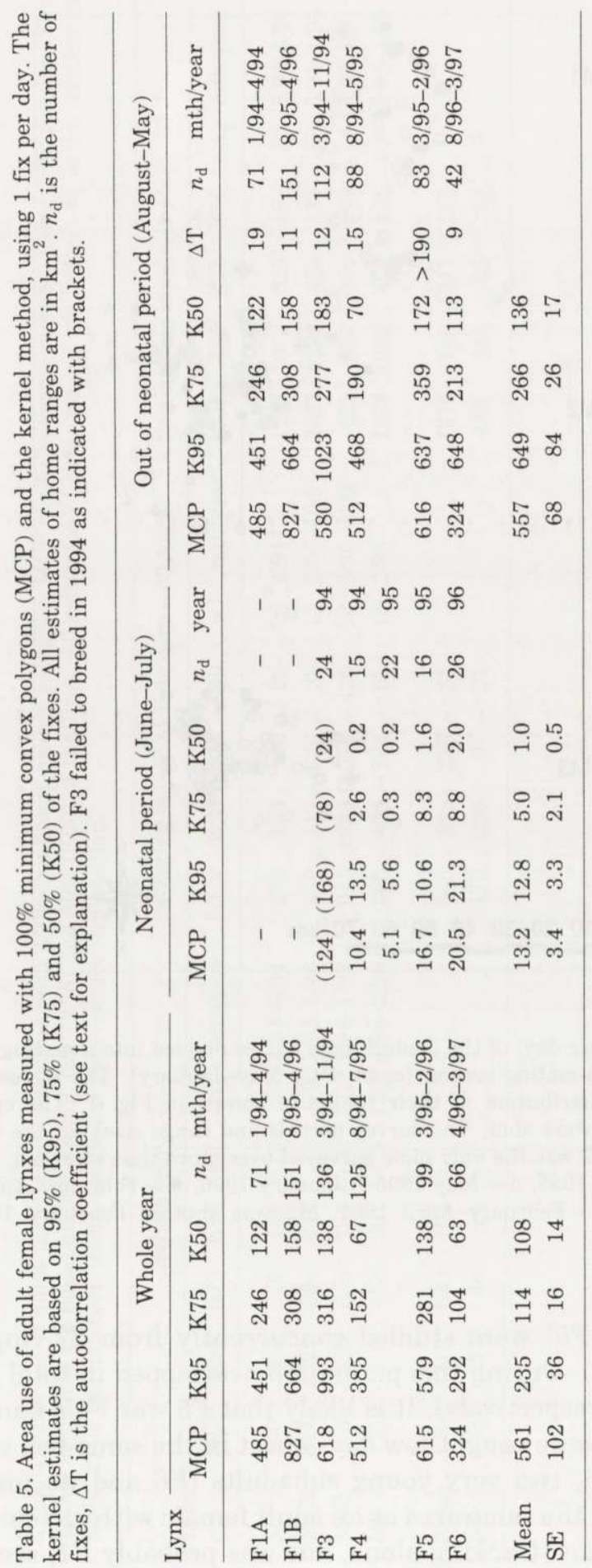




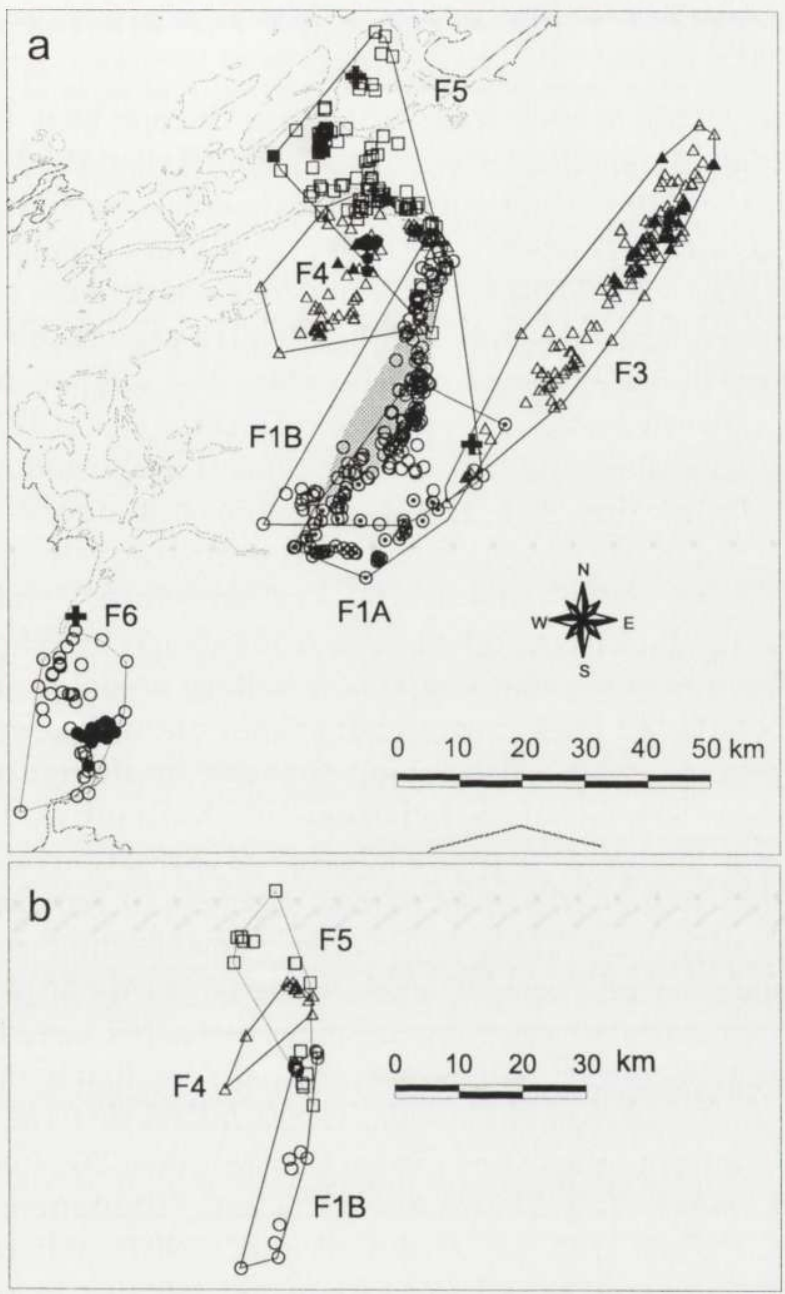

Fig. 5. (a) Spacing (max 1 fix per day) of adult female lynxes. Monitoring periods and range sizes of the different females are shown in Tables 1 and 4 . F1 was surveyed through 2 separate periods (A and B). Filled dots indicate locations during the neonatal lair period (June-July), open dots indicate locations from the rest of the year. The shaded polygon shows the range of 2 grown, motherless kittens (F6 and a sibling) in March-April 1995, shared with an untagged female with offspring, presumably F1. The crosses indicate the locations where F3, F5 and F6 were shot (F3 and F6 were killed after the end of the survey). (b) The relative spacing of 3 adult females with offspring all tracked 22 August -6 October 1995. During this period F5 overlapped with F1 and F4.

Two anecdotal cases were observed of verified or presumed antagonistic behaviour against conspecifics. In March 1994, snow tracking revealed subadult F2 to have been chased by another lynx. In February 1999, lynx hunters found M2 mortally wounded by another male, as revealed by the surrounding tracks. 


\section{Discussion}

Previous telemetry studies of lynxes in central Europe have found that males use larger areas than do females (Breitenmoser and Haller 1993, Breitenmoser et al. 1993, Schmidt et al. 1997) and move longer distances each day (Breitenmoser and Haller 1993), as also predicted from theory for solitary carnivores (Erlinge and Sandell 1986, Sandell 1989). These studies also found both sexes to maintain home ranges with extensive inter-sexual, but little intra-sexual, overlap suggesting intra-sexual resource defence through territoriality. The same seems to be common in related species, ie Iberian lynx Lynx pardinus (Ferreras et al. 1997), Canadian lynx Lynx canadensis (Poole 1995) and bobcat Lynx rufus (Lovallo and Anderson 1996).

The present study deviates from the other studies of the same species by being situated in a very northerly environment with comparatively lower densities of prey $\left(<180\right.$ medium-sized ungulates $/ 100 \mathrm{~km}^{2}$ in winter) and predators $(0.5$ lynx $/ 100 \mathrm{~km}^{2}$ in winter, kittens included). This study should therefore provide a good opportunity to study the movement tactics of a solitary predator under low-density conditions. The population was, however, far from naturally regulated, but was probably kept well below natural carrying capacity by human persecution (see Sunde et al. 1998a). The latter is indicated by the hunting mortality of the radio-collared lynxes, but also by the total absence of starvation mortality in kittens and subadults, and by the early onset of reproduction in females, which usually occurred at the age of 2 years (Table 1). Relatively good feeding conditions and/or a large turnover of adults could possibly explain the moderate dispersal distances of subadults (40 km on average) since much longer distances have been reported in other lynx species during periods of food scarcity (eg Canadian lynx; Poole 1997).

The mean range sizes of resident females (100\% MCPs: $561 \mathrm{~km}^{2}$ ) were 2-4 times larger than reported from other sites (Swiss Central Alps: $264 \mathrm{~km}^{2}$, Breitenmoser and Haller 1993; Swiss Jura Mountains: $226 \mathrm{~km}^{2}$, Breitenmoser et al. 1993; Białowieża Forest, Poland: $133 \mathrm{~km}^{2}$, Schmidt et al. 1997). Whereas males on an annual basis used 3.4 times larger areas than did females in this study (100\% MCPs), the ratio elsewhere found to be 3.3 (Breitenmoser and Haller 1993), 1.7 (Breitenmoser et al. 1993) and 1.3 (Schmidt et al. 1997). Not only did central Norwegian lynxes use much larger areas than in other study sites, but also the males tended to use larger areas compared to females than previously reported. Since the densities of medium sized ungulates were 6-8 times lower than those in other study areas (Swiss Alps: 1270/100 km², Breitenmoser and Haller 1987; Białowieża Forest: $1030 / 100 \mathrm{~km}^{2}$, Jędrzejewska et al. 1994) the larger range size of females in mid Norway is probably related to the needs for larger foraging areas. However, the preponderance of alpine habitat in the study area may also have played a role because extensive areas of alpine habitat between valleys with the preferred lowlands were included within the total ranges. Since the relative proportion of alpine habitat increases with the absolute size of the polygon, due to the band-like distribution of lowland, the relatively larger male-female difference 
in total range size compared with previous studies can probably be explained by a larger proportion of alpine habitat in male polygons. The latter is supported by the $75 \%$ and $50 \%$-kernels that show little difference between the sexes. The preference for lowland habitats probably reflects the importance of a reliable prey base (ie relatively resident roe deer in lowlands vs migratory and herd-living reindeer in the highlands) and the requirement of vegetation cover for hunting and day shelter (Sunde et al. 1998b).

The much longer daily movements of males than of females and subadults were probably a tactic to keep in contact with as many females as possible. Even though females probably were not receptive for much more than a month of the year, the males performed long distance movements throughout the year. This is probably also the reason behind the greater carcass wastage by males throughout the year compared to females (Sunde et al. 2000), indicating that males optimised movements over foraging or carcass consumption all year round. This could be an indication of all year territoriality in males, though it does not match the observation that the rut ranges often were smaller than the ranges in the rest of the year (Fig. 4). Alternatively, the ranging behaviour of males outside the rutting season could be their attempt to keep themselves updated on the dispersion and movement of the females for the following rut.

Females with kittens might be constrained in their movements due to the inability of kittens to travel longer distances, but this is less likely since little differences in daily movement existed between females with kittens and subadults or females without kittens. The movement distances of family groups in this study were relatively similar to the daily linear movement distances of family groups in reindeer areas in northern Sweden (Pedersen et al. 1999).

The two cases of intra-specific combats showed that antagonistic behaviour did occur in the population. However, the large ranges with patchy distributions of preferred habitat render territory defence difficult as also indicated by the long $\Delta \mathrm{T}$ intervals (5-23 days) for both sexes. In addition the numerically most abundant prey in winter, reindeer, migrated in herds, which probably made monopolisation of prey less efficient than in areas with resident prey populations. The periodic overlaps of females, the co-occurrence of 2 subadults and 1 resident female in the same area and the floating tendencies of female F5, may indicate that their territory structure was more diffuse than in denser populations, though caution is required in the conclusion, since the data is on case level. It should also be noted that the two adult females that overlapped the most with each other, were likely to be kin. Increased tolerance to kin has previously been recorded in female Canadian lynx (Poole 1995).

For males, the females may be even harder to defend than prey resources since females may see an advantage in escaping monopolisation by a residing male (Davies 1991). Therefore, instead of trying to defend a particular area, an alternative male strategy could be to find as many females as possible (Sandell 1989) and/or to follow certain females in their receptive periods. Since the males usually covered 
smaller areas during the rut seasons than during the rest of the year (Fig. 4), they probably joined the same female for weeks (as also observed in the field, authors' pers. obs.) instead of attempting to exclude other males from a delimited area. The home range shift of the male surveyed over 2 years indicates a low level of area defence in the long term.

Not only the low number of simultaneously studied neighbours but also the intensive hunting of the population hampers the interpretation of the land tenure system in this study. In 1996 and 1997 , ca $1 / 4$ and $1 / 3$ of the population were harvested (Sunde et al. 1998a). In addition to keeping the general lynx density low, hunting may upset the social system by continuously creating empty gaps without territory holders. Disappearance of competing, neighbouring males or females may thus explain the home range shifts in male M2, but does not explain the general reduction in male range size during the rut. The floating home range of female F5 and its overlap with neighbouring females could be explained as a young resident female's unfamiliarity with the neighbouring ranges, whereas the coexistence of two family groups in the same area through several months of late winter is harder to explain as an effect of culling of residents. We therefore believe that at least some of the observed patterns were a result of the low population density alone. However, this should be tested in studies of other boreal lynx populations that are targets for less human persecution than the one investigated here.

Acknowledgements: We are grateful to J. P. Bolstad, K. Brøndbo, A. K. Frie, T. Ingerslev, M. Kjørstad, C. Moshøj, K. Nybakk, K. M. Rosendal, S. L. Rosendal, G. Saxer, S. Ø. Stener and many volunteer students and local residents for assisting with radio-tracking. P. Ott and F. Hovey made the SAS-program for composite analysis of randomisations. T. Nygård commented a previous draft of this manuscript and K. G. Poole, K. Schmidt and an anonymous referee improved the final version with their comments. J. Andersen and E. Hvass polished the language. The study was funded with grants from the Research Council of Norway (NFR), The Directorate for Nature Management (DN) and the Norwegian Institute for Nature Research (NINA).

\section{References}

Aebischer N. J., Robertson P. A. and Kenward R. E. 1993. Compositional analysis of habitat use from animal radio-tracking data. Ecology 74: 1313-1325.

Breitenmoser U. and Haller H. 1987. Zur Nahrungsökologie des Luchses Lynx lynx in den schweizerischen Nordalpen. Zeitschrift für Säugetierkunde 52: 168-191.

Breitenmoser U. and Haller H. 1993. Patterns of predation by reintroduced European lynx in the Swiss Alps. The Journal of Wildlife Management 57: 135-144.

Breitenmoser U., Kaczensky P., Dötterer M., Breitenmoser-Würsten C., Capt S., Bernhart F. and Liberek M. 1993. Spatial organisation and recruitment of lynx (Lynx lynx) in a reintroduced population in the Swiss Jura mountains. Journal of Zoology, London 231: 449-464.

Davies N. B. 1978. Ecological questions about territorial behaviour. [In: Behavioural ecology, an evolutionary approach (1st ed.). J. R. Krebs and N. B. Davies, eds]. Blackwell Scientific Publications Inc., Oxford: $317-350$.

Davies N. B. 1991. Mating systems. [In: Behavioural ecology, an evolutionary approach (3rd ed.). J. R. Krebs and N. B. Davies, eds]. Blackwell Scientific Publications Inc., Oxford: 263-294.

De Solla S. R., Bonduriansky R. and Brooks R. J. 1999. Eliminating autocorrelation reduces biological relevance of home range estimates. Journal of Animal Ecology 68: 221-234. 
Erlinge S. and Sandell M. 1986. Seasonal changes in the social organization of male stoats, Mustela erminea: an effect of shifts between two decisive resources. Oikos 47: 57-62.

Ferreras P., Beltran J. F., Aldama J. J. and Delibes M. 1997. Spatial organisation and land tenure systems of the endangered Iberian lynx (Lynx pardinus). Journal of Zoology, London 243: 163-189.

Harris S., Cresswell W. J., Forde P. G., Trewhella W. J., Woollard T. and Wray S. 1990. Home-range analysis using radio-tracking data - a review of problems and techniques particularly as applied to the study of mammals. Mammal Review 20: 87-123.

Heptner V. G. and Sludskiï A. A. 1972. Luchs, Felis (Lynx) lynx Linneaeus, 1758. [In: Die Säugetiere der Sowietunion III: Raubtiere (Feleonidae). V. G. Heptner and N. P. Naumov, eds. German translation by Feurich R. F. (1980)]. Gustav Fischer Verlag, Jena: 413-493.

Jędrzejewska B., Okarma H., Jędrzejewski W. and Miłkowski L. 1994. Effects of exploitation and protection on forest structure, ungulate density and wolf predation in Białowieża Primeval Forest, Poland. Journal of Applied Ecology 31: 664-676.

Johnson D. H. 1980. The comparison of usage and availability measurements for evaluating resource preference. Ecology 61: 65-71.

Kenward R. E. and Hodder K. H. 1996. Ranges V. An analysis system for biological location data. Institute of Terrestrial Ecology, Dorset, Wareham, UK.

Kvam T. 1984. Age determination in the European lynx (Lynx l. lynx) by incremental lines in tooth cementum. Acta Zoologica Fennica 171: 221-223.

Lovallo M. J. and Anderson E. M. 1996. Bobcat (Lynx rufus) home range size and habitat use in northwest Wisconsin. American Midland Naturalist 135: 241-252.

Manly B. F. 1997. Randomization, bootstrap and Monte Carlo methods in biology (2 ed). Chapman \& Hall, London: 1-399.

Mohr C. O. 1947. Table of equivalent populations of North American small mammals. American Midland Naturalist 37: 223-249.

Nowel K. and Jackson P. 1996. Wild cats: status survey and action plan. UICN Publications, Gland: 1-382.

Nybakk K., Kjørstad M., Overskaug K., Kvam T., Berntsen F., Linell J. B. and Andersen R. 1996. Experiences with live-capture and radio collaring of lynx in Norway. Fauna Norvegica A 17: 17-26.

Pedersen V. A., Linnell J. D. C., Andersen R., Andren H., Linden M. and Segerström P. 1999. Winter lynx predation on semi-domestic reindeer in northern Sweden. Wildlife Biology 5: 203-211.

Poole K. G. 1995. Spatial organisation of a lynx population. Canadian Journal of Zoology 73: 632-641.

Poole K. G. 1997. Dispersal patterns of lynx in the Northwest Territories. The Journal of Wildlife Management 61: 497-505.

Sandell M. 1989. The mating tactics and spacing patterns of solitary carnivores. [In: Carnivore behaviour, ecology and evolution. J. L. Gittleman, ed]. Chapman \& Hall, London: 146-182.

Schmidt K., Jędrzejewski W. and Okarma H. 1997. Spatial organisation and social relations in the Eurasian lynx population in Białowieża Primeval Forest, Poland. Acta Theriologica 42: 298-312.

Sunde P., Overskaug K. and Kvam T. 1998a. Culling of lynxes related to livestock predation in a heterogeneous landscape. Wildlife Biology 4: 169-175.

Sunde P., Stener S. Ø. and Kvam T. 1998b. Tolerance of resting lynxes to humans. Wildlife Biology 4: 177-183.

Sunde P., Kvam T., Bolstad J. P. and Bronndal M. 2000. Foraging by lynxes in a managed boreal-alpine environment. Ecography 23: 291-298.

Swihart R. K. and Slade N. A. 1985. Testing for independence of observations in animal movements. Ecology 66: 1176-1184.

Worton B. J. 1989. Kernel methods for estimating the utilisation distribution in home range studies. Ecology 70: 164-168.

Received 7 December 1999, accepted 18 April 2000. 
Appendix. Availability and use of habitats of radio-collared lynxes. SB - south boreal vegetation, MB middle boreal vegetation, NB - north boreal vegetation, and AL - alpine vegetation (see text for definitions). Habitat selection on 3rd order level was calculated for nine lynxes with data from 14 or more aerial fixes. Moreover, data on 3rd order availability from lynx M4 was included in the analysis of habitat selection on the 2nd order level. $U_{s}$ - Composition of habitats used in summer (16 May - 15 November), $U_{w}$ - composition of habitats used in winter (16 November - 15 May), $A_{3}$ - composition of habitats available on 3rd order level (semi-random points, see text), $\mathrm{A}_{2}$ - habitat composition of the $6700 \mathrm{~km}^{2}$ study area (Fig. 1) used as available habitat on the 2nd order level, HEI - habitat elevation index based on mean ranks of the habitats by increasing elevation (ranked increasingly from $\mathrm{SB}=1$ to $\mathrm{AL}=4) \cdot n$ - number of telemetry fixes on lynxes sampled from fixed-wing aircraft or semi-random fixes generated in a Geographic Information System (in brackets).

\begin{tabular}{|c|c|c|c|c|c|c|c|}
\hline \multirow{2}{*}{ Lynx } & \multirow{2}{*}{ Data } & \multicolumn{4}{|c|}{ Habitat category } & \multirow{2}{*}{ HEI } & \multirow{2}{*}{$n$} \\
\hline & & SB & MB & NB & $\mathrm{AL}$ & & \\
\hline \multirow[t]{3}{*}{ M1 } & $\mathrm{U}_{\mathrm{s}}$ & 0.600 & 0.200 & 0.200 & 0.000 & 1.60 & 5 \\
\hline & $\mathrm{U}_{\mathrm{w}}$ & 0.444 & 0.556 & 0.000 & 0.000 & 1.56 & \\
\hline & $\mathrm{A}_{3}$ & 0.220 & 0.489 & 0.237 & 0.054 & & (186) \\
\hline \multirow[t]{3}{*}{ M2 } & $\mathrm{U}_{\mathrm{s}}$ & 0.105 & 0.526 & 0.368 & 0.000 & 2.26 & 19 \\
\hline & $\mathrm{U}_{\mathrm{w}}$ & 0.000 & 0.500 & 0.458 & 0.042 & 2.54 & 24 \\
\hline & $\mathrm{A}_{3}$ & 0.071 & 0.365 & 0.322 & 0.243 & & $(482)$ \\
\hline \multirow[t]{3}{*}{ M3 } & $\mathrm{U}_{\mathrm{s}}$ & 0.455 & 0.545 & 0.000 & 0.000 & 1.55 & 11 \\
\hline & $\mathrm{U}_{\mathrm{w}}$ & 0.500 & 0.357 & 0.143 & 0.000 & 1.64 & 14 \\
\hline & $\mathrm{A}_{3}$ & 0.236 & 0.426 & 0.261 & 0.078 & & (339) \\
\hline \multirow[t]{3}{*}{ M4 } & $\mathrm{U}_{\mathrm{s}}$ & - & - & - & - & - & 0 \\
\hline & $\mathrm{U}_{\mathrm{w}}$ & 0.750 & 0.000 & 0.250 & 0.000 & 1.50 & \\
\hline & $\mathrm{A}_{3}$ & 0.200 & 0.342 & 0.316 & 0.142 & & (155) \\
\hline \multirow[t]{3}{*}{$\mathrm{F} 1$} & $\mathrm{U}_{\mathrm{s}}$ & 0.174 & 0.826 & 0.000 & 0.000 & 1.83 & 23 \\
\hline & $\mathrm{U}_{\mathrm{w}}$ & 0.200 & 0.600 & 0.200 & 0.000 & 2.00 & \\
\hline & $\mathrm{A}_{3}$ & 0.158 & 0.392 & 0.281 & 0.169 & & (609) \\
\hline \multirow[t]{3}{*}{ F2 } & $\mathrm{U}_{\mathrm{s}}$ & 0.222 & 0.722 & 0.056 & 0.000 & 1.83 & 18 \\
\hline & $\mathrm{U}_{\mathrm{w}}$ & 0.500 & 0.400 & 0.100 & 0.000 & 1.60 & 10 \\
\hline & $\mathrm{A}_{3}$ & 0.170 & 0.399 & 0.327 & 0.104 & & (318) \\
\hline \multirow[t]{3}{*}{ F3 } & $\mathrm{U}_{\mathrm{s}}$ & 0.000 & 0.333 & 0.667 & 0.000 & 2.67 & 9 \\
\hline & $\mathrm{U}_{\mathrm{w}}$ & 0.000 & 0.733 & 0.267 & 0.000 & 2.27 & 15 \\
\hline & $\mathrm{A}_{3}$ & 0.006 & 0.429 & 0.429 & 0.157 & & (357) \\
\hline \multirow[t]{3}{*}{$\mathrm{F} 4$} & $\mathrm{U}_{\mathrm{s}}$ & 0.000 & 0.615 & 0.385 & 0.000 & 2.39 & 13 \\
\hline & $\mathrm{U}_{\mathrm{w}}$ & 0.045 & 0.500 & 0.455 & 0.000 & 2.41 & 22 \\
\hline & $\mathrm{A}_{3}$ & 0.046 & 0.346 & 0.350 & 0.258 & & (260) \\
\hline \multirow[t]{3}{*}{ F5 } & $\mathrm{U}_{\mathrm{s}}$ & 0.000 & 0.611 & 0.389 & 0.000 & 2.39 & 18 \\
\hline & $\mathrm{U}_{\mathrm{w}}$ & 0.125 & 0.313 & 0.313 & 0.250 & 2.69 & 32 \\
\hline & $\mathrm{A}_{3}$ & 0.088 & 0.318 & 0.336 & 0.259 & & (456) \\
\hline \multirow[t]{3}{*}{ F6 } & $\mathrm{U}_{\mathrm{s}}$ & 0.133 & 0.733 & 0.133 & 0.000 & 2.00 & 15 \\
\hline & $\mathrm{U}_{\mathrm{w}}$ & 0.150 & 0.650 & 0.200 & 0.000 & 2.05 & 20 \\
\hline & $\mathrm{A}_{3}$ & 0.205 & 0.474 & 0.224 & 0.098 & & (523) \\
\hline Study area & $\mathrm{A}_{2}$ & 0.09 & 0.28 & 0.36 & 0.23 & & \\
\hline
\end{tabular}

